\title{
FAKTOR-FAKTOR YANG BERHUBUNGAN DENGAN MINAT PETANI KENTANG UNTUK MENABUNG DI BANK SYARIAH KECAMATAN PANGALENGAN KABUPATEN BANDUNG
}

\section{FACTORS RELATED TO THE INTEREST OF POTATO FARMERS TO SAVE IN SHARIA BANK PANGALENGAN SUB-DISTRICT, BANDUNG DISTRICT}

\author{
Ega Yunita Sari*, Eliana Wulandari \\ Universitas Padjadjaran, Jl. Raya Bandung Sumedang KM. 21 \\ *E-mail: egayunita10@gmail.com \\ (Diterima 29-12-2020; Disetujui 14-1-2021)
}

\begin{abstract}
ABSTRAK
Bank syariah merupakan bagian dari lembaga keuangan syariah yang menawarkan jasa sebagai penghimpun dana (funding). Petani dapat ikut mengakses fasilitas dari bank syariah. Kecamatan Pangalengan merupakan daerah yang dikenal dengan hasil pertaniannya, yaitu kentang. Mayoritas penduduknya bekerja sebagai petani. Aktivitas menabung petani kentang di bank syariah masih rendah, petani lebih banyak menabung pada bank konvensional. Minat menabung petani pada bank syariah dapat dipengaruhi oleh beberapa faktor. Tujuan penelitian ini untuk menganalisis faktorfaktor yang berhubungan dengan minat petani kentang untuk menabung di bank syariah Kecamatan Pangalengan. Penelitian ini menggunakan metode survei dengan analisis data deskriptif kuantitatif dan regresi linear berganda. Penelitian ini menunjukkan hasil bahwa faktor pelayanan, pengetahuan, pendapatan usahatani dan promosi memiliki hubungan secara signifikan dengan minat petani kentang untuk menabung di bank syariah Kecamatan Pangalengan, Kabupaten Bandung.
\end{abstract}

Kata Kunci: Minat Menabung, Bank Syariah, Petani Kentang, Faktor-faktor

\section{ABSTRACT}

Sharia banks are part of Islamic financial institutions that offer services as funding. Farmers can participate in accessing facilities from Sharia banks. Pangalengan District is an area known for the agricultural products, namely potatoes. The majority of the population works as farmers. Saving carried out by potato farmers in sharia banks are still low, farmers are saving more in conventional banks. Farmers' interest in saving in sharia banks can be influenced by several factors. This study aimed to determine the factors related to the interest of potato farmers' to save in sharia banks in Pangalengan District. This research used survey method using quantitative descriptive data and multiple linear regression analysis. This research indicated that services, knowledge, farming income, and promotion are significantly related to the interest of potato farmers' to save in sharia banks in Pangalengan Sub-District, Bandung District.

Keywords: Interest in Saving, Sharia Bank, Potato Farmers, Factors.

\section{PENDAHULUAN}

Negara Indonesia termasuk ke dalam 10 negara dengan jumlah penduduk Islam terbesar di dunia (Global Religious Future, 2010). Pada tahun 2010 tercatat bahwa jumlah penduduk Islam di Indonesia mencapai 207.176.162 jiwa, angka tersebut akan mengalami peningkatan secara signifikan pada tahun 2020. Menurut Hidayat (2018), 
peningkatan jumlah penduduk Islam di Indonesia berpeluang dalam mengembangkan nilai aset ekonomi syariah. Ditunjukkan pada Tabel 1 bahwa Negara Indonesia menduduki peringkat Tabel 1. Islamic Finance Country Index, 2019

\begin{tabular}{lcccccc}
\hline \multicolumn{1}{c}{ Negara } & Skor 2019 & Skor 2018 & Perubahan skor & $\begin{array}{c}\text { Peringkat } \\
\mathbf{2 0 1 9}\end{array}$ & $\begin{array}{c}\text { Peringkat } \\
\mathbf{2 0 1 8}\end{array}$ & $\begin{array}{c}\text { Perubahan } \\
\text { peringkat }\end{array}$ \\
\hline Indonesia & 81,93 & 24,13 & $+57,80$ & 1 & 6 & +5 \\
Malaysia & 81,05 & 81,01 & $+0,04$ & 2 & 1 & -1 \\
Iran & 79,03 & 79,01 & $+0,02$ & 3 & 2 & -1 \\
Saudi Arabia & 60,65 & 66,66 & $-6,01$ & 4 & 3 & -1 \\
Sudan & 55,71 & 17,09 & $+38,62$ & 5 & 11 & +6 \\
Brunei Darussalam & 49,99 & 10,11 & $+39,88$ & 6 & 14 & +8 \\
United arab emirates & 45,31 & 39,78 & $+5,53$ & 7 & 4 & -3 \\
Bangladesh & 43,01 & 17,78 & $+25,23$ & 8 & 10 & +2 \\
Kuwait & 40,90 & 37,67 & $+3,23$ & 9 & 5 & -4 \\
Pakistan & 36,88 & 24,01 & $+12,87$ & 10 & 7 & -3
\end{tabular}

pertama dengan skor 81,93 dalam data Islamic finance country index. Hal tersebut membuktikan bahwa Indonesia dapat mengembangkan industri keuangan syariah.

Sumber: Global Islamic Finance Report, 2019

Lembaga keuangan syariah yang sudah tidak asing dikenal oleh masyarakat umum adalah bank syariah. Indonesia mendirikan perbankan syariah pertama yaitu Bank Muamalat sejak tahun 1992. Peningkatan jumlah peminat pada perbankan syariah terjadi pada masa setelah krisis keuangan global pada tahun 2008 (Musri \& Rama, 2015). Perbankan syariah memiliki potensi kuat untuk dapat berkembang sejalan dengan peningkatan jumlah bank syariah di Indonesia setiap tahunnya. Menurut Otoritas Jasa Keuangan (2019) tercatat bahwa jumlah bank umum syariah mengalami peningkatan dari tahun 2016 sebanyak 13 unit menjadi 14 unit pada tahun 2019. Bank syariah merupakan perantara yang menyediakan jasa keuangan untuk masyarakat umum di mana semua aktivitas didasarkan pada etika dan prinsip hukum islam seperti tidak memiliki unsur riba (bunga), tidak ada spekulasi yang tidak produktif (maysir), tidak ada aktivitas mencurigakan (garrar), tidak ada kasus yang tidak sah (salah), dan hanya mendanai jenis usaha yang sah dan halal (Pertiwi \& Ritonga, 2012).

Perbankan syariah memiliki tujuan sebagai penghimpun dana (funding) atau dikenal dengan produk tabungan. Menurut Antonio (2002), penghimpunan dana yang dilakukan oleh bank syariah memiliki prinsip yang berbeda dengan bank konvensional. Bank syariah 
menggunakan prinsip sesuai syariat Islam yaitu mudharabah (bagi hasil) dan wadiah (titipan). Sedangkan bank konvensional menggunakan prinsip bunga. Jenis produk tabungan yang ditawarkan oleh bank umum syariah yaitu mudharabah deposit dan tabungan wadiah. Sementara itu jenis tabungan pada Bank Perkreditan Rakyat Syariah meliputi tabungan IB Ka'bah dan tabungan kurban. Cakupan bagi Bank Perkreditan Rakyat Syariah lebih sempit dibandingkan dengan bank umum syariah (Soemitra, 2017). Menurut Pandey \& Swasdpeera (2012), motivasi utama dalam menabung yaitu untuk memenuhi konsumsi dimasa yang akan datang. Tujuan menabung tidak hanya sebatas mengumpulkan uang tetapi dapat menggunakannya kembali untuk sesuatu yang diinginkan (Garbinsky et al, 2014).

Sejalan dengan pernyataan tersebut menurut Amudha \& Varathan (2015) menabung dapat meningkatkan pertumbuhan dan perkembangan ekonomi bagi negara. Perbankan syariah memberikan fasilitas kepada masyarakat untuk dapat melakukan tindakan menabung. Setiap calon nasabah perbankan memiliki daya tarik masingmasing terhadap perbankan yang akan diakses. Menurut Maski (2010), calon nasabah akan menentukan bank berdasarkan keuntungan dan kemudahan yang diberikan oleh pihak perbankan. Ditunjukkan pada Tabel 2 mengenai dana komposisi Dana Pihak Ketiga (DPK) bank umum syariah per Desember tahun 2016-2019.

Tabel 2. Komposisi Dana Pihak Ketiga Bank Umum Syariah Tahun 2016-2019 (Rp Miliar)

\begin{tabular}{|c|c|c|c|c|c|}
\hline \multirow{2}{*}{$\begin{array}{c}\text { Jenis Dana Pihak } \\
\text { Ketiga }\end{array}$} & \multicolumn{4}{|c|}{ Komposisi Dana Pihak Ketiga Bank Umum Syariah (Miliar) } & \multirow{2}{*}{ Total } \\
\hline & Des 2016 & Des 2017 & Des 2018 & Des 2019 & \\
\hline Giro & 19.652 & 26.411 & 27.554 & 42.076 & 115.693 \\
\hline Tabungan & 64.733 & 74.629 & 88.044 & 100.659 & 328.065 \\
\hline Simpanan Berjangka & 122.022 & 137.353 & 142.008 & 146.243 & 547.626 \\
\hline Total DPK & 206.407 & 238.393 & 257.606 & 288.978 & 991.384 \\
\hline
\end{tabular}

Sumber: Otoritas Jasa Keuangan 2016-2019

Tabel 2 menunjukkan jumlah dana tabungan pada bank umum syariah di Indonesia terjadi peningkatan dari tahun 2016-2019. Artinya masyarakat di
Indonesia sudah mulai menggunakan perbankan syariah sebagai tempat untuk menabung maupun akses pembiayaan. 
Perkembangan lembaga keuangan berkaitan dengan pembangunan ekonomi negara. Sektor keuangan memiliki peran penting terhadap pembangunan ekonomi dan berkembangnya lembaga keuangan hasil dari pertumbuhan ekonomi (King \& Levine, 1993). Salah satu sektor lainnya yang memiliki peran terhadap pembangunan ekonomi adalah sektor pertanian (Kementerian Pertanian, 2018). Daerah sentra produksi kentang terbesar di Kabupaten Bandung salah satunya adalah Kecamatan Pangalengan (BPS, 2020). Tingkat produksi kentang pada tahun 559.962 ton pada tahun 2019 (BPS, 2020). Petani merupakan salah satu pelaku dalam sektor pertanian. Mayoritas penduduk di Kecamatan Pangalengan bekerja sebagai petani. Sebagai pelaku dalam pembangun ekonomi negara sudah seharusnya dapat ikut serta dalam menikmati perkembangan lembaga keuangan. Petani dapat ikut serta menikmati produk dari perbankan syariah. Namun, pada kenyataannya masih sedikit petani yang menggunakan perbankan syariah untuk menabung maupun akses pembiayaan. Petani memiliki sifat rasional, berpikir kreatif dengan keinginan yang tinggi, namun tidak bisa tercapai karena terbatasnya kemampuan (Popkin, 1979).
Sebagian petani di Kecamatan Pangalengan yang memiliki kemampuan pengetahuan tentang perbankan syariah menggunakan BPRS Amanah Rabbaniah untuk kebutuhan menabung dan akses pembiayaan.

Berbagai faktor yang dapat mempengaruhi petani untuk berminat dalam menabung khususnya di bank syariah. Menurut Hafsah (2016) faktor stabilitas ekonomi dapat mendorong untuk meningkatkan keinginan individu dalam menabung. Tingkat pendapatan berpengaruh positif dalam minat menabung seseorang (Castaldi \& Zoli, 2012). Pendapatan usahatani yang didapatkan petani seharusnya dapat dialokasikan sebagian untuk ditabung. Petani kentang Pangalengan mendapatkan penerimaan hasil usahatani dengan total sejumlah Rp 131.946.193 per hektar per musim pada tahun 2019 (Rahmah \& Wulandari, 2020). Besarnya penerimaan tersebut seharusnya dapat disimpan sebagian untuk ditabung. Hasil tabungan dapat petani gunakan dalam membantu modal usahatani ataupun pada kebutuhan yang mendadak. Pengetahuan petani terhadap bank syariah dapat dikategorikan masih rendah. Petani lebih banyak memahami sistem pada bank konvensional sehingga memudahkan 
petani untuk mengaksesnya. Pengetahuan memiliki komponen sosial dan faktorfaktor sosial sebagai pendukung (Cohen, 2012). Tingkat pengetahuan seseorang dapat menjadi faktor pendorong untuk melakukan suatu tindakan (Maski, 2010). Pengetahuan yang luas dapat memudahkan seseorang dalam menentukan keputusan dalam bertindak. Adapun faktor lainnya yang dapat memberikan pengaruh terhadap minat menabung konsumen seperti promosi, pelayanan, lokasi dan kondisi lingkungan. Penelitian ini bertujuan untuk mengetahui faktor-faktor apa saja yang berhubungan secara signifikan dengan minat petani kentang untuk menabung dan menggunakan bank syariah pada dua desa penelitian yang berada di Kecamatan Pangalengan.

\section{METODE PENELITIAN}

Penelitian menggunakan populasi petani kentang di Desa Pangalengan dan Desa Pulosari, Kecamatan Pangalengan yang tergabung ke dalam Gapoktan Pangalengan dan Gapoktan Pulosari. Lokasi penelitian diambil berdasarkan Kecamatan Pangalengan sebagai sentra produksi kentang terbesar di Kabupaten Bandung. Kecamatan Pangalengan juga terdapat lembaga keuangan konvensional dan syariah. Adapun sampel yang digunakan sebanyak 52 responden yang dihitung dengan stratified random sampling. Penelitian ini menggunakan metode survei dengan analisis data deskriptif kuantitatif dan regresi linear berganda. Perhitungan bobot tanggapan responden terhadap item instrument menggunakan alat ukur skala likert. Skala likert adalah alat untuk mengukur perilaku individu dengan menanggapi butir pertanyaan dengan pilihan setiap butir pertanyaan terdiri atas 5 (Rensis Likert, 1932). Penggunaan bobot skala likert dalam penelitian ini adalah :

- Tidak Setuju $=1$

- Kurang Setuju $=2$

- Netral = 3

- Setuju $=4$

- Sangat Setuju $=5$

Menurut Mona et al (2015), suatu penelitian yang memiliki variabel independen lebih dari satu harus menggunakan metode analisis regresi linear berganda. Variabel independen pada penelitian terdiri atas pelayanan $\left(\mathrm{X}_{1}\right)$, kondisi lingkungan $\left(\mathrm{X}_{2}\right)$, lokasi $\left(\mathrm{X}_{3}\right)$, pengetahuan $\left(\mathrm{X}_{4}\right)$, pendapatan usahatani $\left(\mathrm{X}_{5}\right)$, dan promosi $\left(\mathrm{X}_{6}\right)$. Variabel dependen yang digunakan yaitu minat petani kentang untuk menabung di 
bank syariah Kecamatan Pangalengan

(Y). Model persamaan regresi linear berganda yang digunakan yaitu sebagai berikut:

$$
\begin{gathered}
Y=\beta 0+\beta_{1} X_{1}+\beta_{2} X_{2}+\beta_{3} X_{3}+\beta_{4} X_{4}+ \\
\beta_{5} X_{5}+\beta_{6} X_{6}+e
\end{gathered}
$$

Keterangan:

$\mathrm{Y}=$ Minat petani kentang untuk menabung di lembaga keuangan syariah

$\beta \mathrm{o}=$ Intersep

$\mathrm{X}_{1}=$ Pelayanan

$\mathrm{X}_{2}=$ Kondisi Lingkungan

$\mathrm{X}_{3}=$ Lokasi

$\mathrm{X}_{4}=$ Pengetahuan

$\mathrm{X}_{5}=$ Pendapatan Usahatani

$\mathrm{X}_{6}=$ Promosi

$\mathrm{e}=$ Standard Error

Hipotesis penelitian yang akan dianalisis yaitu sebagai berikut:

1. $\mathrm{H}_{0}=$ Faktor pelayanan tidak berhubungan dengan minat petani kentang untuk menabung di bank syariah.

$\mathrm{H}_{1}=$ Faktor pelayanan berhubungan dengan minat petani kentang untuk menabung pada bank syariah.

2. $\mathrm{H}_{0}=$ Faktor kondisi lingkungan tidak berhubungan dengan minat petani kentang untuk menabung pada bank syariah.

$\mathrm{H}_{1}=$ Faktor kondisi lingkungan berhubungan dengan minat petani kentang untuk menabung di bank syariah.

3. $\mathrm{H}_{0}=$ Faktor lokasi tidak berhubungan dengan minat petani kentang untuk menabung di bank syariah.

$\mathrm{H}_{1}=$ Faktor lokasi berhubungan dengan minat petani kentang untuk menabung pada bank syariah.

4. $\mathrm{H}_{0}=$ Faktor pengetahuan tidak berhubungan dengan minat petani kentang untuk menabung pada bank syariah.

$\mathrm{H}_{1}=$ Faktor pengetahuan berhubungan dengan minat petani kentang untuk menabung pada bank syariah.

5. $\mathrm{H}_{0}=$ Faktor pendapatan usahatani tidak berhubungan dengan minat petani kentang untuk menabung di bank syariah.

$\mathrm{H}_{1}=$ Faktor pendapatan usahatani berhubungan dengan minat petani kentang untuk menabung di bank syariah.

6. $\mathrm{H}_{0}=$ Faktor promosi tidak berhubungan dengan minat petani kentang untuk menabung di bank syariah.

$\mathrm{H}_{1}=$ Faktor promosi berhubungan dengan minat petani kentang untuk menabung di bank syariah. 


\section{HASIL DAN PEMBAHASAN}

\section{Karakteristik Responden}

Karakteristik responden adalah jenis data yang dihasilkan dari identitas responden penelitian (Lubis \& Hidayat, 2015).

Tabel 3. Data Karakteristik Umur Responden

\begin{tabular}{lcc}
\hline $\begin{array}{c}\text { Karakteristik } \\
\text { Umur }\end{array}$ & $\begin{array}{c}\text { Jumlah } \\
\text { Responden } \\
\text { (Jiwa) }\end{array}$ & $\begin{array}{c}\text { Persentase } \\
(\%)\end{array}$ \\
\hline 16-35 tahun & 7 & 13 \\
36-55 tahun & 33 & 63 \\
56-75 tahun & 12 & 23 \\
\hline
\end{tabular}

Sumber: Data Primer 2020 (diolah)

Pada Tabel 3 ditunjukkan bahwa mayoritas responden memiliki umur pada skala 36-55 tahun. Rata-rata umur responden adalah 47 tahun. Menurut Ulfah et al (2013) tingkat umur produktivitas seseorang yaitu 16-64 tahun. Sehingga terdapat sebanyak 33 petani yang tergolong kategori umur produktif. Adapun Tabel 4 menunjukkan data kepemilikan rekening tabungan.

Tabel 4. Data Kepemilikan Rekening Tabungan

\begin{tabular}{lcc}
\hline \multicolumn{1}{c}{ Indikator } & $\begin{array}{c}\text { Jumlah } \\
\text { Responden } \\
\text { (Jiwa) }\end{array}$ & $\begin{array}{c}\text { Persentase } \\
\mathbf{( \% )}\end{array}$ \\
\hline $\begin{array}{l}\text { Bank syariah } \\
\text { Bank }\end{array}$ & 7 & 13,5 \\
$\begin{array}{l}\text { konvensional } \\
\begin{array}{l}\text { Rekening } \\
\text { keduanya } \\
\text { Tidak memiliki } \\
\text { rekening }\end{array}\end{array}$ & 31 & 59,6 \\
$\begin{array}{l}\text { Sumber: Data Primer 2020 (diolah) } \\
\text { Sumber }\end{array}$ &
\end{tabular}

Berdasarkan data yang ditunjukkan pada Tabel 4 dapat disimpulkan bahwa responden lebih banyak mengakses pada bank konvensional sebanyak 31 orang atau $59,6 \%$ dari total responden. Sementara itu, petani yang menggunakan bank syariah hanya $14 \%$ atau 7 orang dari total keseluruhan. Yoko \& Prayoga (2019) menyatakan bahwa pemahaman petani terhadap sistem perbankan syariah dalam sudut pandang islam masih rendah. Maka petani lebih banyak menggunakan bank konvensional karena lebih memahami sistem yang dijalankan.

\section{Karakteristik Usahatani}

Karakteristik usahatani yang diamati yaitu luas lahan, pendapatan usahatani, dan pengalaman usahatani. Pada Tabel 5 ditunjukkan rata-rata setiap variabel karakteristik usahatani.

Tabel 5. Nilai Rata-rata Karakteristik Usahatani

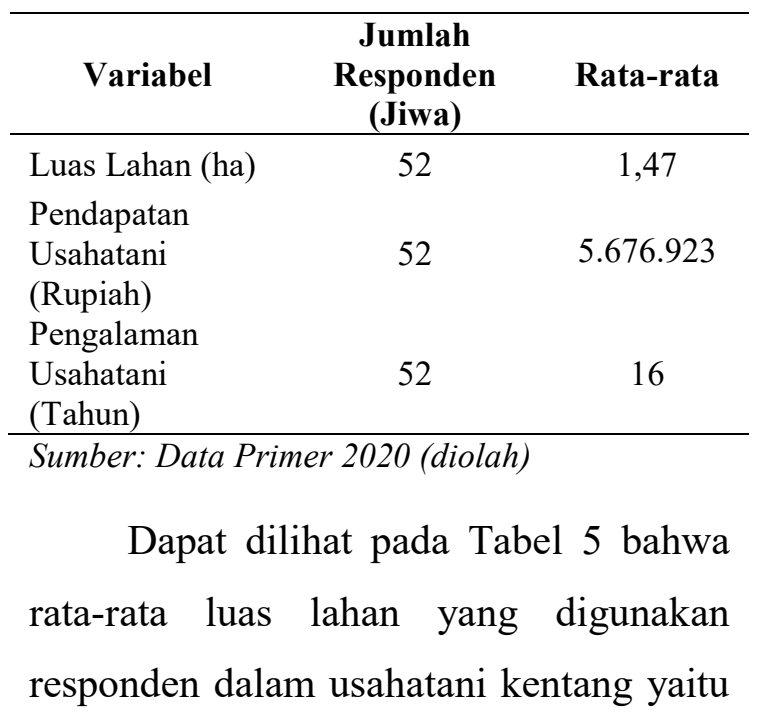


1,47 ha dalam satu kali musim tanam. Artinya luas lahan yang dimiliki responden tergolong kategori lahan luas. Menurut (Harini et al., 2019) luas lahan dapat mempengaruhi produksi pertanian. Semakin luas lahan pertanian yang digarap maka peluang jumlah produksi yang didapatkan semakin besar (Maramba, 2018).

Luas lahan yang dimiliki petani dapat mempengaruhi pendapatan. Pendapatan usahatani adalah hasil yang diterima oleh petani dalam mengelola usahatani. Menurut Listiani et al. (2019) luas lahan dapat mempengaruhi pendapatan, sehingga semakin luas lahan garapan maka pendapatan akan meningkat. Pada tabel 7 menunjukkan rata-rata pendapatan petani dalam usahatani adalah Rp 5.676.923 dalam waktu satu bulan. Pendapatan usahatani memiliki nilai yang berfluktuatif, tergantung pada kondisi harga pasar, luas lahan dan kualitas produksi.

Pada Tabel 5 diketahui bahwa ratarata mayoritas pengalaman responden dalam usahatani kentang yaitu 16 tahun. Pengalaman merupakan faktor yang dapat membantu meningkatkan kualitas diri seseorang dalam bidang pekerjaan (Purnamasari \& Hernawati, 2017). Sehingga semakin lama pengalaman dalam usahatani kentang, maka dapat membantu petani dalam meningkatkan kemampuan dan kualitas dirinya pada bidang yang digeluti.

\section{Minat Petani Untuk Menabung di \\ Bank Syariah}

Pada dasarnya minat petani untuk menabung dipengaruhi oleh beberapa faktor. Faktor -faktor tersebut yang dapat mendorong seseorang untuk melakukan suatu tindakan. Menurut (Rusdianto \& Ibrahim, 2017) minat adalah perilaku seseorang yang berkaitan dengan sikap ketertarikannya terhadap sesuatu. Minat menabung merupakan rasa ketertarikan yang timbul dalam diri dan mendorong untuk melakukan tindakan menabung.

\begin{tabular}{lcc}
\multicolumn{3}{c}{ Tabel 6. Ketertarikan Petani untuk Menabung } \\
\hline $\begin{array}{l}\text { Ketertarikan Petani } \\
\text { untuk Menabung }\end{array}$ & $\begin{array}{c}\text { Jumlah } \\
\text { Petani } \\
\text { (jiwa) }\end{array}$ & $\begin{array}{c}\text { Persentase } \\
\text { (\%) }\end{array}$ \\
\hline $\begin{array}{l}\text { Tertarik menabung di } \\
\text { Bank syariah } \\
\text { Tertarik menabung di }\end{array}$ & 5 & 9,6 \\
$\begin{array}{l}\text { Bank konvensional } \\
\text { Tertarik menabung } \\
\text { pada keduanya } \\
\text { Tidak tertarik } \\
\text { menabung di } \\
\text { perbankan }\end{array}$ & 31 & 26,9 \\
\hline \multicolumn{1}{c}{ Total } & 2 & 39,6 \\
\hline
\end{tabular}

Sumber: Data Primer 2020 (diolah)

Pada Tabel 6 mengindikasikan bahwa petani yang tertarik dan berminat untuk menabung pada bank syariah hanya 5 orang atau $9,6 \%$ dari total responden. Mayoritas petani tetap berminat 
menabung pada bank konvensional dengan jumlah sebanyak 14 orang atau 26,9\%. Hal tersebut terjadi karena terdapat faktor-faktor yang mempengaruhi diri seseorang untuk minat menabung.

\section{Analisis Regresi Linear Berganda}

Pada penelitian ini diduga bahwa faktor-faktor yang dapat mempengaruhi minat menabung petani yaitu pelayanan,

Tabel 7. Output Analisis Regresi Linear Berganda

\begin{tabular}{|c|c|c|c|c|c|c|}
\hline & \multirow[t]{2}{*}{ Model } & \multicolumn{2}{|c|}{$\begin{array}{c}\text { Unstandardized } \\
\text { Coefficients } \\
\end{array}$} & \multirow{2}{*}{$\begin{array}{l}\text { Standardized } \\
\text { Coefficients } \\
\text { Beta }\end{array}$} & \multirow[b]{2}{*}{$\mathbf{t}$} & \multirow[b]{2}{*}{ Sig. } \\
\hline & & B & Std. Error & & & \\
\hline \multirow[t]{7}{*}{1} & (Constant) & 0,984 & 1,186 & & 0,829 & 0,411 \\
\hline & Pelayanan $(\mathrm{X} 1)$ & 0,370 & 0,113 & 0,282 & 3,278 & $0,002^{*}$ \\
\hline & Kondisi Lingkungan(X2) & 0,047 & 0,073 & 0,036 & 0,653 & 0,517 \\
\hline & Lokasi(X3) & $-0,051$ & 0,079 & $-0,035$ & $-0,638$ & 0,527 \\
\hline & Pengetahuan (X4) & 0,296 & 0,101 & 0,239 & 2,914 & $0,006^{*}$ \\
\hline & $\begin{array}{l}\text { Pendapatan usahatani } \\
\text { (X5) }\end{array}$ & 0,380 & 0,133 & 0,271 & 2,855 & $0,006^{*}$ \\
\hline & Promosi(X6) & 0,399 & 0,108 & 0,279 & 3,685 & $0,001 *$ \\
\hline
\end{tabular}

Sumber: Output software SPSS (2020)

Berdasarkan perhitungan hasil analisis pada Tabel 7 menunjukkan bahwa model persamaan regresi linear berganda sebagai berikut:

$$
\begin{gathered}
Y=0,984+0,370 X_{1}+0,047 X_{2}-0,05 \\
X_{3}+0,296 X_{4}+0,380 X_{5}+0,399 X_{6}+e
\end{gathered}
$$

Hasil analisis pada Tabel 9 dapat membuktikan bahwa faktor-faktor yang dapat mempengaruhi minat untuk menabung secara signifikan adalah lokasi, kondisi lingkungan, pengetahuan, pendapatan usahatani dan promosi. Alat bantu analisis menggunakan software SPSS dan Microsoft Excel. Pada tabel 9 ditunjukkan hasil output analisis regresi linear berganda dan model persamaannya yang telah diuji. 
melakukan aktivitas menabung pada bank syariah. Berdasarkan penelitian Pertiwi \& Ritonga (2012) bahwa faktor pelayanan memiliki pengaruh yang positif dan signifikan terhadap pengambilan keputusan untuk menabung di bank muamalat. Pelayanan menjadi salah satu faktor yang dilihat oleh konsumen saat akan memutuskan untuk menggunakan suatu jasa. Maka dari itu faktor pelayanan penting dalam meningkatkan minat konsumen. Semakin baik pelayanan yang diberikan oleh bank syariah kepada konsumen maka dapat meningkatkan minat petani kentang khususnya dalam menggunakan dan menabung di bank tersebut.

2. Hubungan Variabel Pengetahuan dengan Minat Menabung

Nilai signifikansi variabel pengetahuan sebesar 0,006 yang lebih kecil dari 0,05 dengan $\mathrm{T}_{\text {hitung }}$ lebih besar dari $\mathrm{T}_{\text {tabel }}$ yaitu 2,914. Artinya variabel pengetahuan memiliki hipotesis $\mathrm{H}_{0}$ diterima dan $\mathrm{H}_{1}$ ditolak sehingga faktor pengetahuan memiliki hubungan secara positif dan signifikan dengan minat petani kentang untuk menabung di bank syariah. Menurut Chadijah et al. (2014) pengetahuan menjadi faktor timbulnya suatu tindakan dari seseorang. Petani di lokasi penelitian mayoritas sudah mengetahui mengenai bank syariah. Hasil penelitian ini selaras dengan pernyataan Rosyid \& Saidiah (2016) yang membuktikan tingkat pengetahuan seorang santri dan guru secara positif dan signifikan mempengaruhi minat untuk menabung pada perbankan syariah. Tingkat pengetahuan petani yang tinggi petani dalam memahami sistem bank syariah maka dapat meningkatkan minat menabung pada bank tersebut. Tingkat pengetahuan yang luas memudahkan seseorang dalam menentukan suatu pilihan. Ketika pengetahuan terhadap bank syariah sudah baik maka petani akan lebih mudah dalam menentukan keputusannya dalam menggunakan bank syariah untu menabung.

3. Hubungan Variabel Pendapatan Usahatani dengan Minat Menabung Nilai signifikansi sebesar 0,006 yang lebih kecil dari 0,05 dengan $\mathrm{T}_{\text {hitung }}$ lebih besar dari $\mathrm{T}_{\text {tabel }}$ yaitu 2,855. Hipotesis penelitian dinyatakan $\mathrm{H}_{0}$ diterima dan $\mathrm{H}_{1}$ ditolak, sehingga faktor pendapatan usahatani secara positif dan signifikan memiliki hubungan dengan minat petani kentang untuk menabung di bank syariah. Hasil tersebut sejalan dengan pernyataan Maghfiroh (2018) 
bahwa tingkat pendapatan dapat mempengaruhi secara signifikan keputusan seorang santri untuk menabung. Artinya semakin tinggi tingkat pendapatan seseorang maka dapat meningkatkan minat konsumen terhadap aktivitas menabung.

4. Hubungan Variabel Promosi dengan Minat Menabung

Variabel promosi memiliki nilai signifikansi sebesar 0,001 yang lebih kecil dari 0,05 dengan $\mathrm{T}_{\text {hitung }}$ lebih besar dari $\mathrm{T}_{\text {tabel }}$ yaitu 3,685. Hipotesis dinyatakan $\mathrm{H}_{0}$ diterima dan $\mathrm{H}_{1}$ ditolak. Dapat disimpulkan bahwa faktor promosi secara positif dan signifikan memiliki hubungan dengan minat petani kentang untuk menabung di bank syariah. Pernyataan tersebut didukung oleh hasil penelitian Pratiwi \& Soesanto (2016) faktor promosi menjadi hal yang penting untuk mendapatkan penilaian positif bagi perusahaan dan terbukti meningkatkan minat menabung nasabah. Semakin baik dan menarik promosi yang di berikan oleh bank syariah maka dapat membantu dalam meningkatkan minat menabung konsumen khususnya pada petani.

\section{KESIMPULAN DAN SARAN}

Berdasarkan hasil penelitian menunjukkan bahwa minat petani kentang untuk menabung di bank syariah masih rendah dibuktikan dari jumlah petani yang tertarik masih sedikit. Adapun faktor pelayanan, pengetahuan, pendapatan usahatani dan promosi memiliki nilai positif serta berhubungan signifikan dengan minat petani kentang untuk menabung dan menggunakan bank syariah.

Petani diharapkan agar dapat menabung untuk dapat membantu dalam usahatani. Petani diharapkan dapat meningkatkan kualitas dan jumlah produksi agar terjadi peningkatan pendapatan yang dapat menimbulkan ketertarikan untuk menabung. Begitupun untuk bank syariah disarankan melakukan pendekatan sosialisasi dan meningkatkan promosi untuk meningkatkan minat petani untuk menabung di bank syariah Kecamatan Pangalengan.

\section{DAFTAR PUSTAKA}

Amudha, J., \& Varathan, V. A. (2015). Savings and Investment Behavior of Rural Household in Salem. International Journal of Multidisciplinary Research and Development.

Castaldi, G., \& Zoli, M. (2012). The Willingness to Save and the distribution of income: an empirical analysis on energy saving and its determinants. 11th Journées LouisAndré Gérard-Varet. 
Cohen, S. (2012). Knowledge and Context. Journal of Philosophy, Inc., 83(10), 574-583.

Garbinsky, E. N., Klesse, A. K., \& Aaker, J. (2014). Money in the bank: Feeling powerful increases saving. Journal of Consumer Research, 41(3), 610-623.

Hafsah. (2016). Worship Practice and Willingness to Saving Money at Syari'ah Bank. Journal of Humanities and Social Science, 21(4), 13-19.

Harini, R., Ariani, R. D., Supriyati, S., \& Satriagasa, M. C. (2019). Analisis Luas Lahan Pertanian Terhadap Produksi Padi Di Kalimantan Utara. Jurnal Kawistara, 9(1), 15.

Hidayat, Y. R. (2018). Analisis Peluang Dan Tantangan Lembaga Keuangan Syariah Untuk Meningkatkan Daya Saing Menghadapi Masyarakat Ekonomi Asean. Amwaluna: Jurnal Ekonomi Dan Keuangan Syariah.

King, R. G., \& Levine, R. (1993). Finance and growth: schumpeter might be right. Quarterly Journal of Economics, 108(3), 717-737.

Listiani, R., Setiadi, A., \& Santoso, S. I. (2019). Analisis Pendapatan Usahatani Pada Petani Padi Di Kecamatan Mlonggo Kabupaten Jepara. Agrisocionomics: Jurnal Sosial Ekonomi Pertanian, 3(1), 50-58.

Lubis, D., \& Hidayat, R. (2015). Pengaruh Citra Merek dan Harga terhadap Keputusan Pembelian pada Sekolah Tinggi Ilmu Manajemen Sukma Medan. Jurnal Manajemen, 5(1), 15-24.

Maghfiroh, S. (2018). Pengaruh Religiusitas, Pendapatan, Dan Lingkungan Sosial Terhadap Minat Menabung Di Bank Syariah Pada Santri Pesantren Mahasiswi Darush Shalihat. Jurnal Pendidikan Dan Ekonomi, 7(3), 213-222.
Maramba, U. (2018). Pengaruh Karakteristik Terhadap Pendapatan Petani Jagung Di Kabupaten Sumba Timur (Studi Kasus: Desa Kiritana, Kecamatan Kambera, Kabupaten Sumba Timur). Jurnal Ekonomi Pertanian Dan Agribisnis (JEPA), 2, 94-101.

Maski, G. (2010). Analisis Keputusan Nasabah Menabung: Pendekatan Komponen Dan Model Logistik Studi Pada Bank Syariah Di Malang. Journal of Indonesian Applied Economics. https://doi.org/10.21776/ub.jiae.201 0.004 .01 .4

Mona, M., Kekenusa, J., \& Prang, J. (2015). Penggunaan Regresi Linear Berganda untuk Menganalisis Pendapatan Petani Kelapa. Studi Kasus: Petani Kelapa Di Desa Beo, Kecamatan Beo Kabupaten Talaud. D'CARTESIAN. https://doi.org/10.35799/dc.4.2.201 5.9211

Musri, M., \& Rama, A. (2015). Analisis Perilaku Deposan Perbankan di Indonesia: Studi Kasus Bank Syariah dan Konvensional. The Journal of Tauhidinomics.

Pandey, I. M., \& Swasdpeera, P. (2012). Phenomenology of willingness to save: a study of Thai salaried individuals. J. for International Business and Entrepreneurship Development.

Pertiwi, D., \& Ritonga, H. (2012). Analisis Minat Menabung Masyarakat Pada Bank Muamalat Di Kota Kisaran. Jurnal Ekonomi Dan Keuangan, 1(1), 14868.

Pratiwi, D., \& Soesanto, H. (2016). Analisis Pengaruh Atirbut Tabungan, Mutu Tabungan dan Promosi Penjualan Terhadap Citra Perusahaan Dalam Meningkatkan Minat Menabung Nasabah ( Studi kasus pada Bank Jateng Cabang 
Kordinator Semarang ). Diponegoro Journal Of Management, 5, 1-15.

Purnamasari, D., \& Hernawati, E. (2017). Pengaruh Etika Auditor, Pengalaman, Pengetahuan Dan Perilaku Disfungsional Terhadap Kualitas Audit. Jurnal $\mathrm{NeO}-\mathrm{Bis}$, 7(2), 1-17.

Rahmah, S. A., \& Wulandari, E. (2020). Keragaan Produksi Dan Harga Kentang Di Kecamatan Pangalengan, Kabupaten Bandung. Mimbar Agribisnis: Jurnal Pemikiran Masyarakat Ilmiah Berwawasan Agribisnis, 6(1), 265. https://doi.org/10.25157/ma.v6i1.31 39

Rensis Likert. (1932). A technique for the measurement of attitudes. Archives of Psychology.

Rosyid, M., \& Saidiah, H. (2016). Pengetahuan Perbankan Syariah dan Pengaruhnya terhadap Minat Menabung Santri dan Guru. Journal Of Islam Economics, Business and Finance, 7(2), 37-45.
Rusdianto, H., \& Ibrahim, C. (2017). Pengaruh Produk Bank Syariah Terhadap Minat Menabung Dengan Persepsi Masyarakat Sebagai Variabel Moderating Di Pati. Equilibrium: Jurnal Ekonomi Syariah. https://doi.org/10.21043/equilibriu m.v4i1.1837

Ulfah, N., Joko, P., Irfan, N. (2013). Model Kuantitatif Manajemen Kelelahan dan Beban Kerja untuk Peningkatan Produktivitas Pekerja Penggilingan Padi Quantitative Models of Fatigue and Workload Management for Improving Productivity of Rice Milling Labors. Kesehatan Masyarakat Nasional, 7, 477-480.

Yoko, B., \& Prayoga, A. (2019). Understanding Farmers' Access and Perception To Islamic Microfinance on Agricultural Financing: Study in Central Lampung Regency. Journal of Halal Product and Research, 2(1), 6. 